\section{Radical medicine in Beersheba}

\section{from Nechemia Meyers}

ISRAEL's fourth medical school, attached to the Ben-Gurion University of the Negev, opened this month in Beersheba with a first-year class of 34 students, two of them Arabs.

Was there any justification for yet another medical school in a country with the world's highest ratio of physicians to potential patients (about three per thousand) and hundreds of students at existing schools, not to speak of the 1,500 Israelis studying medicine in Europe? Many people, particularly those connected with the other three medical schools, think not. But thanks to the missionary zeal of its chief advocate, Professor Moshe Prywes, it is now an established fact.

Prywes, connected for many years with the Hebrew University Medical School in Jerusalem, is determined to develop a very different kind of institution at the Ben-Gurion University, of which he is president.

$\mathrm{He}$ wants to use the new school as a means of breaking down the barriers that now exist between academic medical centres on one hand, and neighbourhood clinics on the other. At present, Israel's best qualified doctors, graduates of her own medical schools, cluster around the universities and university-affiliated hospitals, leaving day-to-day medical care to be dispensed mainly by old-timers and new immigrants. And the neighbourhood doctors, being effectively cut off from hospitals and research centres, tend to practice out-of-date, conveyorbelt medicine-which makes them frustrated and their patients dissatisfied.

Prwyes aims to ensure that the graduates of his school are different by training them to be patient-oriented from the outset. For example, the schools calls for students to work in clinics and hospitals, under the supervision of special tutors, from their very first. year.

Internship will also be handled in a new way. Instead of becoming interns at the end of their studies, the fledgling medicos will spend a full year working in the field, albeit with limited responsibilities, midway through their course.

The Ben-Gurion University Medical School, unlike others in Israel, will play down basic biological research, emphasising instead research linked to the specific health problems of the community. While not in any way denying its importance, the directors of the new school advise would-be students who are primarily interested in research to enrol elsewhere.

This same philosophy is reflected in the selection of members of faculty, among whom are men who have never written a scientific paper in their lives. In Prywes's opinion, physicians who have proved themselves as lecturers and as doctors in the field are as qualified to be professors as are research-oriented MDs with dozens of papers to their credit.

These unorthodox professors, it is hoped, will set an example for their students. "Hitherto," Prywes has pointed out, "neither the medical student nor the resident saw his teachers working outside the hospital or the research laboratory. Thus talking to students about the importance of community medicine was bound to be a waste of time. They could hardly be convinced of the significance of something their own mentors ignored."

\section{Stormy weather hits Mexican research}

Floods and very early frosts have destroyed several years' worth of research at the International Wheat and Maize Improvement Center, the internationally renowned plant breeding institute run by Norman E. Borlaug in Mexico. Frost killed off most of the hybrid wheat and maize being bred at two research stations near Mexico City early in September, and floods associated with hurricane Fifi completely devasted a third station in eastern Mexico three weeks later.

In most cases the crops-which represented the results of two or three years of cross breeding-were destroyed before they had produced seed for planting next year. According to Dr Robert Osler, deputy director of the center, there is no reserve seed from intermediate hybrids so it will be necessary to go right back to the original strains and cross breed them again over the next two or three years to reproduce the destroyed plants.

Osler said that up to $80 \%$ of the wheat and the entire maize crop was destroyed at a station at Toluca near Mexico City by frosts which arrived several weeks earlier than usual. The same frosts also wiped out most of the maize at another station on the other side of Mexico City, although much of the wheat crop there survived. Osler fears, however, that because the frost caught the plants at a relatively early stage the seeds may be difficult to germinate.

Flood damage to the third station is more serious. Torrential rain associated with hurricane Fifi-the one which devastated Honduras-caused a river to burst its banks and flood fields at a research station located at Poza Rica to a depth of 3 metres. Osler said that the water took the topsoil off a large area and flooded silos and machinery sheds.

Osler estimated that it could take at least a year to repair the damage, one problem being that replacing the topsoil could introduce a good deal of variability in soil condition. The Center has applied to the Consultative Group, an international group of donors which supports crop breeding research, for funds to repair the damage. There is also a possibility that a European government may provide at least part of the money.

\section{Rhodesia rules}

"The University [of Rhodesia] has been exempted by the British Government and others from sanctions." So runs the last sentence of a sheet describing Salisbury, its university and the chair of biochemistry which was being advertised recently. What does this mean in practice? One of our readers enquired of the Foreign Office in London and got the following replies:

Can I convent European currency into Rhodesian currency? Travellers to Rhodesia are normally only permitted to take $£ 25$ in sterling notes.

What personal goods can I take? Household and personal effects, but not cars.

Can I order and receive scientific research equipment? Export to Rhodesia is prohibited except by licence issued only for humanitarian reasons (religious, educational or medical). Each application is considered separately; present policy is to give "sympathetic consideration to applications from the University of Rhodesia".

Can I advertise in the United Kingdom for technical and administrative personnel? Only under licence (the same criteria apply as above). Present policy is to issue licences for academic but not for other posts.

Can I seek research grants in the United Kingdom? Nothing prevents you, but the transfer of funds is subject to strict exchange control ruleseach case is considered on its merits.

Can I change Rhodesian currency back into other currencies? It cannot be exchanged in the United Kingdom. "I cannot say what facilities are available in Rhodesia."

He's not going.

We called the Foreign Office for clarification of some items and they draw attention to two points. First, nothing can be taken for granted in dealing with the United Kingdom from Rhodesia. There are no automatic exemptions and everything has to be reviewed. Second, there is no British representative in Rhodesia, so none of the customary consular facilities either of a routine or an emergency nature are available. 